\title{
The Relevance of Information and Communication Technology in Enhancing Representative Democracy in Nigeria
}

\author{
Chris Ifeanyi Adebowale OKE (Ph.D.) \\ Lecturer, Dept. of Political Science \& Public Admin, Edo University Iyamho, Edo state \\ Violet E. ATUFE-MUSA \\ Department of Political Science, Delta State College of Physical Education, Mosogar
}

\begin{abstract}
The paper examines the concept of representative democracy and election as its foundational hallmark. It focuses on election in Nigeria and the role of information and communication Technology (ICT). Elections in Nigeria and the nature of the electoral process are usually fraught with sectarian conflicts between ethnic groups and the multivariate religions that exist thereby exposing the process to violence and fraud which consequently have led to perennial leadership failures. This paper therefore, aims to x-ray the role and relevance of ICT in affecting the outcomes of elections in Nigeria. In particular, it seeks to examine how the deployment of advanced technology in the form of introduction of card readers and permanent voters card (PVC) can enhance the electoral process and management. There is also the revolutionary impact of the social media on election and voters' awareness with more engaging and participatory conversations through various social platforms that have helped to shape public opinions and reposition elections not only in Nigeria but also in other climes. Communication and diffusionist theories are adopted as the theoretical framework. The findings reveal that innovation in the management of elections especially by introducing ICT will lead to minimal electoral fraud and more credible elections that will be acceptable to both the contestants, electorate and the international community. The paper recommends that government must play the leading role to ensure ICT is fully deployed in the conduct of elections in Nigeria. It further recommends that government should create the enabling environment to investors both local and foreign to engender competitive innovation in the area of software and IT development. The Nigerian youth are ICT savvy and if given the opportunity, will develop more suitable technology that could be used to solve the perennial electoral conundrum.
\end{abstract}

Keywords: Information \& communication technology, New media, Representative democracy, Political participation, Diffusionist approach

DOI: $10.7176 / \mathrm{DCS} / 10-11-07$

Publication date: November $30^{\text {th }} 2020$

\section{Introduction:}

Among the existing forms of governments, representative democracy stands out as the most desired choice the world over. Thus, it is assumed to be the type which the opinion of the citizens find expression and governing power is indirectly exercised through elected representatives. One of the basic foundations of this form of government is election; a process of choosing person(s) into public office(s) by voting or selection. Hence, election and its process is very vital to the legitimacy of any government. Therefore, it is impossible to imagine a democratic system without election or voting process.

Nigeria, like many other African countries, is confronted with a myriad of socio-economic and political problems ranging from gigantic corruption, disproportionate poverty, massive unemployment, insecurity and general underdevelopment. These problems, many believe, are centered on political leadership which is largely determined by election process and its outcome, especially in transiting from one government to another. Elections in Nigeria are usually marred with electoral malpractice and accompanied with violence, intimidation and sometimes, loss of lives and properties. Thus, the chances of this process producing credible leaders have become very doubtful. In the words of Shively (2005), electoral politics in Nigeria tends to bring out sectarian conflict between tribes and regions of different religions and the difficult logistics together with the passion of hostility that an election awakens, leave the process open to violence and fraud.

In addressing the issue of credibility of election which is fundamental to democracy, there is need for orientation geared towards a well informed electorate, enhancing institutional policies and process through instituting a complete information and communication technology process, such as electronic voting. While it may seem like the main stream media (Television, radio and Newspaper) are already playing the role of informing and educating the electorate and even enhancing election processes for years, it did not engage and involve the participation of the youthful electorate like the social media which has revolutionize the media industry does. In fact, Abubakar (2011), argued that there is the absence of serious debate in the conventional media that could make people to learn the substance of issues and policies proposed as well as related arguments, and that this disallows citizens from participating actively in political discourse. 
The advent and development of information and communication technology has bridged the gap between people and culture, penetrating all levels of society, influencing the socio-economic and political sectors of each country, eroding old practices and models and establishing new ones, in fact, the exposure of Nigerians to global happenings especially to western democracies through advanced information technology has raised their expectations and demands on their leaders and governance in general. Today, information and communication technology (ICT) has broken down all known national barriers to the extent that whatever that happens in one country will immediately reverberate around the world in a matter of minutes. This has inadvertently raised the bar in the way and manner politics and administration were hitherto handled.

According to Unwuchola, Adinlewa, and Udeh, (2017), the emergence of information and communication technologies (ICTs) which in turn gave birth to social networking sites had thus brought another paradigm shift in electioneering process. Since Barak Obama broke the world record in the history of ICTs use for political purpose during the 2008 US Presidential elections, many nations and politicians across the globe have continued to embrace the platform to mobilize their citizens and candidates towards active participation in the political process. The place of ICT in the political system cannot be over emphasized. It is a veritable tool for deepening and enhancing representative democracy. It is significant in ensuring an effective and inclusive electoral system. However, its acquisition and applications are not without challenges especially that of low level telephone penetration and uneven access which appear to be insurmountable.

In line with the above, this paper focuses on the relevance of information and communication technology in enhancing democracy in Nigeria with a focus on the electoral process.

\section{ICT and representative democracy: conceptual and theoretical underpinning.}

Information and communication technology (ICT) is a term that covers all technical means of processing and communicating information. In the opinion of Afriyie (2012), ICTs cover any product that receives, stores, retrieves, manipulates or transmits information electronically in a digital form such as personal computers, digital television, email, robots, etc. It embraces all the uses of digital technology that already exist to help individuals, businesses and organizations use and manipulate information. Similarly, the United Nations Economic Commission for Africa (ECA) (1999), sees ICTs as covering internet service provision, telecommunications equipment and services, information technology equipment and services, media and broadcasting, libraries and documentation centres, commercial information providers, network-based information services, and related information and communication activities.

Ogidan et al (2017), describes it as any technology that powers or enables the storage, processing and information flow within an organization. The modern form of digital ICT includes the computer, the internet, mobile phone and countless innovative applications including social media such as: Facebook, Twitter and WhatsApp, etc. The affordability of ICT tools and systems has made ICT become an important part of almost all aspects of human endeavours. Oladimiji and Folayan (2018), explain that ICT sector has not only grown over the years but has become a catalyst in addressing the needs and interests of low income communities in developing countries.

According to them, the role of ICT includes: reduction of transaction cost, offers immediate connectivity, increases choice of market, widens the geographical scope of potential market and most importantly, as a channel of knowledge and information of all kinds. Ndukwe (2004), puts it more aptly when he explained that ICT has aided the development of all sectors of the society, including social, economic and political spheres. ICTs contribute to economic development and democratisation, including freedom of speech, the free flow of information, promotion of human rights and poverty reduction. ICTs facilitate efficient administration, citizen services, transparency, accountability and formal political participation (e-governance), and also provide the means for social movements, activist groupings or minority groups to engage with these processes on a global level (Association for Progressive Communications, 2009).

It is imperative to state that the platforms of ICTs strengthen the capacity of individuals, aid liberated communication and mobilisation, and reinforce civil society. It enables citizens to report news, expose wrongdoing, express opinions, mobilize protest, monitor elections, scrutinize government, deepen participation, and expand the horizons of freedom (Diamond, 2010). The benefits of these ICTs platforms over older technologies are well documented. For instance, the internet's dispersed nature and capacity to reach large numbers of people promptly, are well suited to grassroots mobilisation. In contrast to television and radio, the new ICTs are two-way and even multi-way forms of communication. Thus, users are not just inert recipients but, journalists, commentators, videographers, entertainers, and organisers. Nigeria has not been left behind in the global deployment of ICTs in everyday human endeavour, especially in relation to governance though not without a few challenges.

Representative democracy is a form of government in which the people exercise governing power indirectly through representatives who are periodically elected. Factors that aid representative democracy include a degree of tolerance, which must exist among range of opinions, participation by the people in social and political 
activities, a degree of political consensus and a well informed electorate. A major factor of the representative government is periodic election. It, however, must be noted that the processes of election are as relevant as the election itself.

Election and its processes include all activities before, during and after. A noteworthy example of a process that affects election credibility is the internal democracy within the political parties that produce the different candidates. It has been observed over time that "God fathers" single-handedly impose the candidates that would contest during party primaries as against majority vote thereby promoting strive and division among party members. This has sometimes led to anti-party activities, rebellion and dissidence among political party members. While this factor may seem unlikely to affect the overall process, it is, however, important to note that every undemocratic procedure compromises election credibility and its outcome eventually.

An important aspect of election is leadership as its product, as noted above, it functions with authority and the cardinal objective of leadership is to provide direction for governance, therefore, the need to emphasize the existing link between election and leadership is very paramount, more so, leadership has majorly been indicated as one of the main factors responsible for the failure of government in Nigeria. In recognition of this, is that the extent to which a leader is able to achieve his mandate is dependent upon support from citizens. Thus, failure is imminent when popular support is absent.

It is very germane to highlight the fact that representative democracy enhances and emboldens political participation. Political participation involves such activities like political discourse, campaigns, party rallies, voter registration, casting of ballots, writing and signing of petitions, attending protests and taking part in civil disobedience, joining interest groups that engage in lobbying, political advocacy, observing and reporting cases of violation of the electoral process such as rigging, intimidation, violence, monetary inducements, underage voting, etc. It encompasses the citizen's involvement in the acts, events or activities that influence the selection of or the actions taken by political representatives. Political participation equally refers to the various mechanisms through which members of the public express their political views and exercise their influence on the political processes including the assessment of those they have selected or elected to represent them at various governmental rungs.

One of the theories which succinctly explains this topic is the diffusionist approach. It explains a process by which innovation is communicated through certain channels over time among members of a social system. Going by the developments in ICT and diversification in the various fields of human endeavour, empirical studies have been conducted in order to ensure a better understanding concerning their diffusion, adoption, acceptance, and usage (Rogers, 1995; Ntemana and Olatokun, 2012). In his diffusion of innovation (DOI) approach, Rogers (2003), maintained that the rate of adoption is substantially influenced by the perceived attributes and innovation characteristics such as: relative advantage, compatibility, trialability, complexity, and observability. Subsequently, four of these characteristics-relative advantage, compatibility, trialability, and observability, as perceived by members of a social system - are positively related to the rate of adoption. However, the complexity of an innovation, as perceived by members of a social system, is adversely related to its rate of adoption.

Let us concisely adumbrate some of these variants. The relative advantage of an innovation is an individual's perception that the innovation will be better, when compared to similar ideas, products, concepts or practices. Those innovations that are perceived to be better and adaptable will be adopted. Compatibility is the awareness that a particular innovation is parallel and congruent with existing understandings of similar or past ideas, products, concepts or practices. Innovations that fit into an individual's existing understanding or scheme will be more easily adopted (Ntemana and Olatokun, 2012). In the opinion of (Rogers, 1995), complexity refers to the belief of how difficult or otherwise the innovation is to understand or follow. It is assumed to be negatively related to the rate of adoption of an innovation. In other words, if an innovation is found to be too complex, it is not easily adopted and may be rejected. Thus, the alternative perspective of this construct is taken, that is, if an innovation is easy to use, it is more likely to be adopted.

Trialability refers to an individual's admittance to an innovation for experiment consequent upon adoption and use. Observability is considered by how available and visible an innovation is to an individual. The idea behind observability is similar to unspoken peer pressure: If an innovation is influential, the observer is more likely to adopt it. Observability leads to a social benchmark at the point where an innovation becomes so pervasive or desirable in a culture that even those who would not normally be users of an innovation may consider to adopt the product (Ntemana and Olatokun, 2012).

It is obvious that the social benefit of ICT like social interactions remain one of the reasons it has been adopted easily and rapidly for electoral purposes in Nigeria. Again, ICT has also reduced inequalities of opportunity between rural areas and the urban dwellers with the introduction of internet services, which swiftly deliver information to remote locations. According to Eregha (2004), this theory sums up the relationship that exists between the developed countries and the third world countries which requires transfer of capital, technology and social structure from the developed states. He argues that the developing countries will develop 
to the extent to which it is determined by the western developed societies.

\section{Information and Communication Technologies (ICTs) and Election Process in Focus.}

While tracing the origin of ICT in the political landscape of Nigeria, Igboechesi (2019), averred that a new political step to information and communication technology (ICT) was first introduced by Independent National Electoral Commission (INEC) in 2003 to register eligible voters and compile credible voters register with a view to consolidating her democracy. The usage of ICT was seen as a very pertinent one, as it was expected to eliminate, primarily the case of multiple registration, which had been one of the main political tools for rigging elections. This unique technique was employed to capture mass involvement in governance and empowerment of the teeming electorates to participate in the electoral processes. The innovation was largely welcomed by Nigerians because it was meant to showcase governance in Nigeria with the fundamental challenge to excel.

Information and communication technologies have greatly impacted on election and its process since the adoption of the Electoral Act 2010. The Act defined the key roles of electronic media to include campaigning, monitoring, educating and involving the electorate in the electoral process. The Electoral Act 2010 which is the legal framework that governs the conduct of elections in Nigeria did not provide specific guidelines on the use of ICTs in elections. Instead, it contains a number of sections that made references to the use of electronic media in the conduct of elections. Meanwhile, a close look at the way the term "electronic media" was used in the Electoral Act indicates that the Act is mindful of the opportunities provided by the electronic media (Policy and Legal Advocacy Centre, 2012). In other words, the Act envisages a key role the electronic media can play in campaigning, monitoring, educating and involving the electorates in electoral processes. Meanwhile, many other technological based reforms have since been introduced to enhance the process since 2010, such as the biometric register of voters and advanced finger print identification system which is considered one of the most recent critical ICT developments in the history of Nigeria election process. It also enabled the introduction of the Electronic Card Reader.

Apart from these achievements, two other key areas of election process which ICT seem to have impacted are voter education and actual voting exercise. The use of ICT for systematic learning and sensitizing the minds of the electorate on their duties and responsibilites as regard modalities of election process and content by the election management bodies (EMBs), civil society organisations and other stakeholders alike has continued to gain momentum with every new election. ICT has become necessary for strengthening and entrenching democratic tenets. For example, the 2015 and 2019 general elections became much popularised due to this technology. The social media facilitated voters' education with the help of Twitter, Facebook, Instagram and WhatsApp. They became platforms for widespread discourse on some national issues, political party manifestoes and even the pedigree of candidates thereby shaping public opinions and increasing political participation. Also, the fact that this medium creates room for instantaneous feedback makes it all the more interesting to the public.

Voting process or exercise is another area of influence by ICT, it refers to the actual voting exercise done within a well stated date and time. The major participants of this process are the electorate (voters) and Independent National Electoral Commission (INEC). This process has been enhanced through information technology by the introduction of Card Reader and the Permanent Voter Card (PVC). The main purpose of these items, amongst others is to reduce election malpractice which manifest in various forms like underage voting, impersonation, vote-buying, etc., which have become associated with every election in Nigeria. Beyond this, another unprecedented development of the impact of information technology on the voting process though not backed up by any extant laws or electoral act, is the amateur video coverage and broadcasting of voting event by electorate to discourage malpractice.

Factors militating against the impact of ICT on electoral process in Nigeria.

While it is obvious that the relevance of ICT to the strengthening of representative democracy through enhancing of the electoral process cannot be over emphasized, it also implies that no meaningful development can take place in any society without a corresponding growth in ICT in the 21 st century. Thus, some challenges to ICT development and its effective impact on the electoral processes are highlighted below.

The issue of electoral policy: The present electoral policy has been criticized for only granting a partial use of technology to the process. A greater measure of the electoral exercise is still manually carried out or resorted to too often, for example, voting, collation and transmission of results. The Electoral Act 2010 did not provide a specific guideline on the role of ICT in election, instead, it contains a number of sections that made references to the use of electronic media. This view was expressed by Legal Advocacy Centre (2011) when it explained that the Act is mindful of the opportunities provided by the electronic media. This could explain the views expressed by National Democratic Institute (2013), that technology can be used to readily create spaces and opportunities for citizens to express their voices, but making these voices politically stronger and the spaces more meaningful is a harder challenge that is political and not technological in nature. 


\section{Cost of information and communication technologies and limited converge:}

The cost of technology is expensive both for the service providers and the users of the product. One reason for this is that ICT infrastructures and backbones are usually not home grown. The challenge here is that very few can afford and use this medium effectively. In addition to this, there is a consensus that most of the wide spread electoral malpractices in Nigeria take place in less covered rural areas where technology is limited and access to it is costly. This creates room for electoral malfeasances.

Poor state of infrastructural facilities: Poor social amenities like electricity has been cited for failure of achieving the desired level of industrialization in the nation. This is also one of the reasons for the failure of ICT in the electoral process. Many observers and stakeholders especially INEC field officers have lamented that the card reader machines do not function most times because of absence of energy to power them. Apart from the inability of the card readers to function effectively, other vital election processes have been hindered due to this factor.

\section{Conclusion}

There is no doubt that developments in ICT have created a platform for democracy to thrive. The mainstream media (television, radio, newspapers) and the social media (Twitter, Facebook, WhatsApp, Instagram and Youtube) have become a force that bridge the gap between people, culture and distance. It has also helped to give voice to such fundamental human rights like freedom of speech and association and more importantly expose activities of government to public scrutiny. Thus, increases in ICT development means high level political culture, increased political participation and ingraining of democratic tenets.

In addition, an information technology policy built on reliable human resources and infrastructures constitutes the fundamental tools and means of assessing, planning, managing development change and achieving sustainable growth. In stating the importance of ICT in the management and conduct of elections, Jega (2012), notes that election management bodies (EMBs) around the world have employed a number of innovative approaches, some of which are now considered best practices, to improve the management and conduct of elections. Electoral reforms that have been instituted include the use of information and communication technology, adoption of more transparent and inclusive processes, professionalization of the organization, amendments to legal framework and improvement of relationships with external stakeholders.

Again, it is important to state that a developing nation like Nigeria that aspires to be taken seriously by the international community and also seeks to participate effectively and become a key player in global political society must ensure acceptable standards in her electoral process to produce legitimate leadership. This can better be achieved through the use of highly efficient information technology in her electoral system which must be driven by a vibrant IT policy.

\section{Recommendations}

- Government should enact electoral policies that reflect mandatory usage of information technology and also ensure the possibility of technology.

- The government and all stakeholders should ensure that there is full digitization of the electoral process and this could be achieved by bringing up a befitting template and incorporating them into our electoral act to give them legal backing.

- Government must as a matter of deliberate policy, guarantee that the country benefits maximally and contributes meaningfully by providing the global solution to the challenges of the information age.

- To encourage and empower Nigerians to participate in the local production and manufacture of software and IT components that are compatible to Nigeria's democratic experience in a competitive manner. In other words, Nigeria should develop and adapt the kind of technology that is relevant and suitable to the local environment.

- There must be a concerted effort to address the electricity problem in Nigeria to boost the development of IT sector and to also power the technological gadgets that will aid the digitalization of electoral process.

\section{Reference}

Abubakar, A. A. (2011). Political participation and discourse in social media during the 2011 Presidential electioneering. Conference paper of ACCE, Covenant University, Ota, Nigeria.

Afriyie, B. S. (2012). Concise ICT fundamentals volume one. USA, Bloomington: Trafford Publishing.

Association for Progressive Communications (2009). ICTs for democracy: Information and communication technologies for the enhancement of democracy - with a focus on empowerment. Stockholm: Swedish International Development Cooperation Agency.

Diamond, L. (2010). Liberation technology. Journal of Democracy, Vol. 21, No. 3.

Eregha, E.E., (2004). National Building in African. Ughelli Eregha Publishers. 
Igboechesi, P. G. (2019). Comprehensive citizens' data and effective elections in Nigeria: The role of information communication technology (ICT). International Journal of Innovative Research \& Development. Vol. 8. Issue 4. April.

Jega, A. M. (2012). Report on the 2011 General Elections. Abuja: Independent National Electoral Commission.

Musa-Atufe, E.V., (2018). Comtemporary Political Analysis: A concise Approach. Benin City. Guide Press.

National Democratic Institute, (2013). Citizen participation and technology: an NDI study. Washington DC: National Democratic Institute for International Affairs.

Ndukwe, E., (2004). The Role of Telecommunication in National Development. Nigerian Tribune. No 13,467. Tuesday 21 September 2004.

Ntemana J. T. and Olatokun, W. (2012). Analyzing the influence of diffusion of innovation attributes on lecturers' attitudes toward information and communication technologies. An Interdisciplinary Journal on Humans in ICT Environments, 8(2).

Policy and Legal Advocacy Centre (2012). Social media and the 2011 elections in Nigeria.

Rogers, E. M. (1995). The origins and development of the diffusion of innovations paradigm as an example of scientific growth. Science Communication, 16(3).

Rogers, E. M. (2003). Diffusion of innovations. New York: The Free Press.

Ogidan, J., Adekola, O., Emmanuel, G., and Okogun O., (2017). Information and communication technology for good governance and socio-development in Nigeria. World Scientific News WSN 72(2017), www.worldscientificnews.com

Shively, W. P. (2005). Power and Choice: An Introduction to Political Science. New York. McGraw Hill.

United Nations Economic Commission for Africa (1999). An overview of ICT trends and policy in Africa. Addis Ababa: UNECA. Retrieved from https://www.un.org/Depts/eca/adf/.

Unwuchola, A. A., Adinlewa, T., and Udeh, Kenneth (2017). An appraisal of the role of ICT as a tool for participatory democracy in Nigeria. MCC, Vol. 1 No. 1, June. 